\title{
Multi-Criteria Decision Analysis for Benchmarking Human-Free Lifting Solutions in the Offshore Wind Energy Environment
}

\author{
Mark Richmond ${ }^{1, *}(\mathbb{D})$, Toby Balaam ${ }^{2}$, Paul Causon ${ }^{1}\left(\mathbb{D}\right.$, Debora Cevasco $^{1}$, Mareike Leimeister ${ }^{1,3}$, \\ Athanasios Kolios ${ }^{1}$ (B) and Feargal Brennan ${ }^{1}$ \\ 1 Offshore Energy Engineering Centre, Cranfield University, Bedfordshire MK43 0AL, UK; \\ P.Causon@cranfield.ac.uk (P.C.); D.Cevasco@cranfield.ac.uk (D.C.); \\ Mareike.Leimeister@cranfield.ac.uk (M.L.); a.kolios@cranfield.ac.uk (A.K.); f.brennan@cranfield.ac.uk (F.B.) \\ 2 Department of Engineering Science, University of Oxford, Parks Road, Oxford OX1 3PJ, UK; \\ Toby.Balaam@wolfson.ox.ac.uk \\ 3 Fraunhofer Institute for Wind Energy Systems IWES, 27572 Bremerhaven, Germany \\ * Correspondence: M.Richmond@cranfield.ac.uk; Tel.: +44-1234-75-8082
}

Received: 19 March 2018; Accepted: 4 May 2018; Published: 7 May 2018

\begin{abstract}
With single components weighing up to hundreds of tonnes and lifted to heights of approximately $100 \mathrm{~m}$, offshore wind turbines can pose risks to personnel, assets, and the environment during installation and maintenance interventions. Guidelines and standards for health and safety in lifting operations exist; however, having people directly beneath the load is still common practice in offshore wind turbine installations. Concepts for human-free offshore lifting operations in the categories of guidance and control, connections, and assembly are studied in this work. This paper documents the process of applying Multi-Criteria Decision Analysis (MCDA), using experts' opinions for the importance of defined criteria obtained by conducting an industry survey, to benchmark the suitability of the concepts at two stages. Stage one streamlined possible options and stage two ranked the remaining suite of options after further development. The survey results showed that criteria such as 'reduction of risk', 'handling improvement' and 'reliability of operation' were most important. The most viable options, weighted by industry opinion, to remove personnel from areas of high risk are: Boom Lock and tag lines, a camera system with mechanical guidance, and automated bolt installation/fastening for seafastening. The decision analysis framework developed can be applied to similar problems to inform choices subject to multiple criteria.
\end{abstract}

Keywords: multi-criteria decision making; Technique for Order of Preference by Similarity to Ideal Solution (TOPSIS); offshore wind turbines; health \& safety; offshore lifting operations

\section{Introduction}

Offshore wind energy has seen considerable investment in the last decade, driven by a growing awareness of the effects of climate change and a need to diversify energy production [1,2]. By the end of 2006 the cumulative installed capacity of European offshore windfarms was approximately $1 \mathrm{GW}$, yet by the end of 2017 the total installed capacity had grown to $15.8 \mathrm{GW}$ [3]. The offshore wind energy industry is set to show continued expansion and it has been estimated that the installed capacity across Europe will reach 25 GW by 2020 [3].

The installation of new turbines and continued maintenance of existing turbines will see the need for frequent onshore and offshore lifting operations. These may range from lifting large wind farm components, such as the tower or nacelle, or smaller loads such as tools, bolts, and bags. 
Whilst current guidelines attempt to preclude personnel from standing or walking below suspended loads this is not always possible. Personnel are frequently beneath lifts to guide loads into position and secure them once in place, as illustrated in Figure 1a, where a team are guiding a suspended tower section into place.

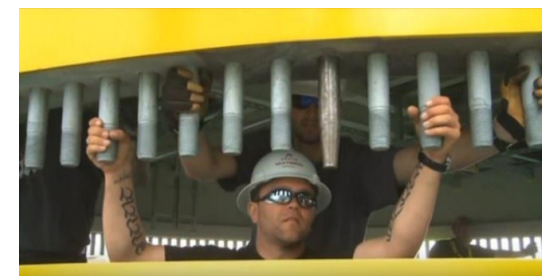

(a)

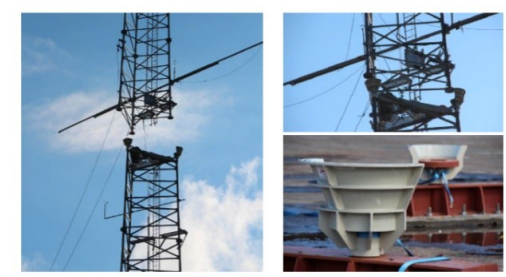

(b)

Figure 1. Examples of mechanical guidance systems: (a) Current use of guide pins; (b) Guide cones for human-free met mast installation [4].

G+ (formerly G9) [5], the offshore wind health and safety organisation, is a consortium of the largest operators each contributing data on all health and safety incidents offshore which are collated into reports [6-8]. Lifting operations are particularly incident prone, consistently coming in the top three most hazardous work processes by incident number. Of these, a high proportion tends to be due to dropped objects.

Table 1 shows the total number of incidents reported each year and, of those, the number of incidents that involved dropped objects. The number of working hours and operations differed from year to year. As such total number of incidents and total number of dropped objects by the number of hours worked for each year have been calculated. This allows for scaled comparisons to be made. From the data, we can see that 2016 saw the highest number of lifting incidents and dropped objects per hour. Although the increase is relatively small it does indicate that the safety of lifts offshore has not improved.

There will always be a degree of risk in lifting operations. The probability and consequence of exposure to such risks may be reduced through careful planning, and procedures and guidelines have been put in place to ensure personnel follow safe practices. However, it is highly unlikely that failures or errors can be prevented or avoided $100 \%$ of the time.

Table 1. Total incidents and dropped objects from 2014 to 2016. [6-8] (Normalized by the number of hours worked and scaled by $10,000,000$.)

\begin{tabular}{cccc}
\hline Area & $\mathbf{2 0 1 4}$ & $\mathbf{2 0 1 5}$ & $\mathbf{2 0 1 6}$ \\
\hline No. of hours worked $\left(\times 10^{6}\right)$ & 23.71 & 21.22 & 21.72 \\
Total incidents-lifting operations & $143(6.0)$ & $100(4.7)$ & $133(6.1)$ \\
Dropped objects-lifting operations & $32(1.3)$ & $28(1.3)$ & $37(1.7)$ \\
\hline
\end{tabular}

In reviewing the detailed incident data made available by $\mathrm{G}+$, it became clear that the most common incidents included dropped objects, such as tools, chains, and bolts. Equipment failure and human error were frequent causes of dropped objects. If such objects were to hit personnel it could result in serious injury or loss of life. Thus, removing personnel from areas where falling objects could land would greatly reduce the risks to personnel.

The aim of this work is to conduct research into and assess the feasibility of methods and technologies that could reduce the need for personnel in the vicinity of lifting operations during installation of offshore wind turbines. This is achieved through employing a widely used Multi-Criteria Decision Analysis (MCDA) method combined with a review of existing technological solutions and recommendations for new ones, and a cross industry survey, which allowed the capturing of real information of the views of operators and practitioners with respect to the criteria importance when it comes to the benchmarking of concepts. 
An MCDA is applied in two stages: the first stage aims to show which alternatives are the most promising and the final stage is to rank the most promising technologies. The target is to not only solve this particular problem but to also demonstrate this methodology which other researchers might apply to their own problems.

The paper is organized as follows: Section 2 presents the concepts being considered and their respective categories. Section 3 gives an introduction to MCDA and discusses the methodology employed, the Technique for Order of Preference by Similarity to Ideal Solution (TOPSIS) method, and the industry survey used to solicit weight values. Section 4 discusses the industry survey and its results, and then follows on with the application of the MCDA. Section 5 presents the results of the MCDA and a discussion. Finally, the conclusions are presented in Section 6.

\section{Wind Turbine Lifting Concepts}

\subsection{Guidance and Control}

In this section a selection of the concepts considered in each of the three categories are presented and, where appropriate, information on the detailed work undertaken is included.

In order to lift single wind turbine components into the correct position, certain guiding and control devices, such as tag lines or guide pins, are already used. However, people are still involved in this lifting procedure; either holding the tag lines and therefore standing in the area where the part is being lifted, or directly within the installed wind turbine part in order to give commands to the crane operator. This is because the operator may not be able to see the connection at certain heights, or to manually push and guide the lifted part into its final correct position.

Mechanical tools can be classified according to their guiding orientation into two groups: guide pins or similar tools for rotational alignment of the bolt holes, and funnels or cones for centralisation. A limited number of bolts can be replaced by 'guide pins', which are slightly longer than the bolts and have a conical end. An example of such a guide pin is presented in Figure 1a. Funnels and cones allow for the centring of two elements. An example of this in practice is that of Figure 1b, where plastic guide cones were used around the flange connection of a met mast to aid the lift [4].

Visual guidance via a suitably placed banksman giving clear orders to the crane operator is simple, effective and, assuming a good protocol is established, safe. For the majority of industries and payloads, successful lifts can be achieved with the banksman positioned close enough to the lifted object without being below the load. When installing offshore wind turbine components this is rarely possible due to the marine environment and nature of the structure, hence the need for banksmen to be in potentially dangerous positions.

Ideas for moving the banksman away from the load whilst keeping the visibility of a local field are mainly based around the use of cameras. This could range from simple cameras attached to the payload, to the use of drones and 360-degree cameras with Virtual Reality (VR).

Sensorial guidance could assist in this area and potentially quantify required movement. Lasers and proximity sensors, used in a variety of applications, could be used to aid depth perception, and are used in industry for dynamic positioning of vessels, pitch and yaw measurements, and distance measurement to locate defects in bearings, shafts etc.

Automated guidance could fully automate the process. Template matching is used in several areas, such as medicine or robotics, in order to detect motions or recognise patterns or images, or also motion tracking is applied [9]. Kaur et al. [10] also studied the positioning of a load and a vehicle by means of image processing and template matching. Smart cameras are already used in robotic guidance for position detection and rotation of elements. Rahman [11] and Rinner and Guggi [12] have used smart cameras to map workshops and control cranes.

Controlling the fine motion of payloads has historically been done using tag lines, which run to the ground and can be controlled by workers below. This becomes difficult during offshore operations where, if controlled by people who are not directly beneath the load, the tag lines are limited to the 
location of the vessel or jack-up platform. Numerous systems are used in practice to control the fine motion and reduce sway, including the 'Boom Lock' [13] and 'Tagline Master' [14]. Additionally, installing components using a floating ship can be made easier through the use of dynamic response simulation [15].

\subsection{Connections}

Bolted flange connections are used in a wide range of construction industries and are a very important part of offshore wind structures. The major components of an offshore wind turbine generator (WTG), i.e., the tower sections, nacelle, and blades, are connected through bolted, ring-flange connections. Seafastening is intrinsically linked to the connection of the components because often the component is fastened to the ship in the same way in which it is fastened in construction. Flanges are welded to the grillage on the ship deck and the component, for example usually the tower section or nacelle, is bolted to the flange. However, bolting and seafastening can lead to a number of potential health and safety issues such as: unsecured loads while bolts are being applied, falling bolts during lifts, and bolts shaking loose in seafastening.

Novel connection types, reducing or eliminating the need for bolts, can be considered. These include friction connections, in which the bolts point radially outwards, are pre-installed and lowered into vertical slots [16]; temporary sliding connections which hold the section pre-bolting; and threaded connections on a large scale.

Hydraulic seafastening could be used to replace bolted connections or provide temporary stability prior to bolting. Various hydraulic systems were considered along with internal jack sea fastening; these employ pistons acting on the inner surface of the transition piece.

One obvious way to remove humans from the line of fire is to automate the tasks performed by humans. This is extremely common in factory manufacturing in a wide variety of industries where the speed, precision, and repeatability of robot machinery have replaced human workers [17]. Converting shop-floor systems to cater for wind turbines was the subject of a conceptual study and included climbing bolt robots and temporary bolting arms.

The use of an Automated Bolting System (ABS) during seafastening was conceptualised by the authors and is shown in Figure 2. Fundamentally, the idea is that if the ABS is positioned in a recess underneath the grillage it could be mounted on a sled which can move between the individual flanges. The advantage of this is that one ABS can be used on the ship and will not require lifting and assembling, as it would to connect tower sections.

Since this work was conducted, a new technology has come on the market from Fistuca called BLUE Wedge which can accomplish both seafastening and a connection technique [18].

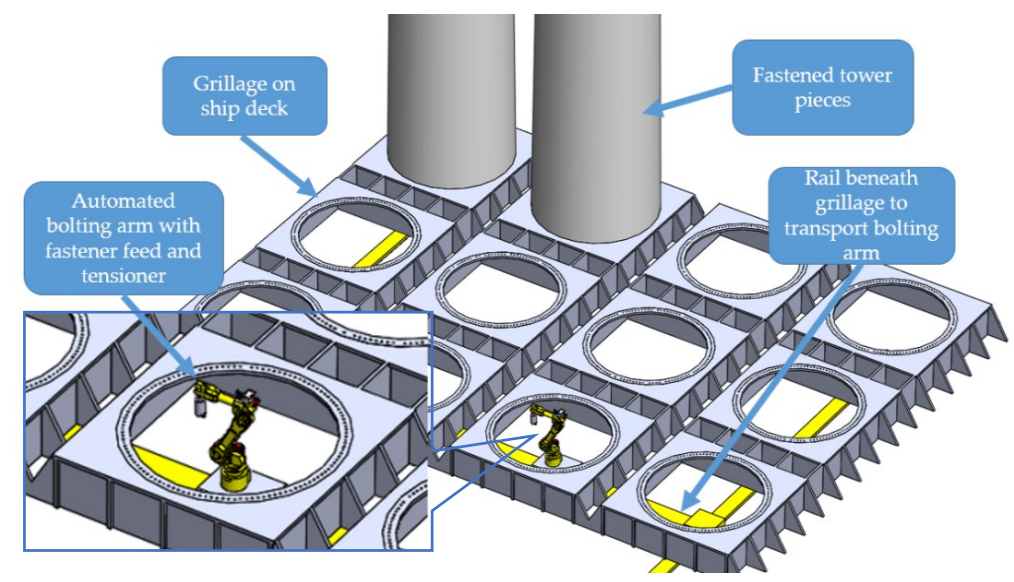

Figure 2. Automated bolted seafastening, concept illustration. 


\subsection{Assembly}

The different offshore pre-assembly transportation and installation methods are the major driving force for a successful wind farm installation [19]. However, as outlined earlier in this paper, human presence beneath heavy lifts is the current procedure and the most hazardous aspect of offshore wind turbine installation operations.

Installation of pre-assembled concepts can be applied as a positive path towards achieving human-free lifting operations offshore, thereby minimising the number of lifts and reducing human exposure to lifting hazards. Pre-assembly, as well as assembly transportation and installation solutions are considered in this section.

Some of the conventional assembly and pre-assembly installation methods of bottom-fixed offshore wind turbines on already installed foundations are shown in Figure 3.

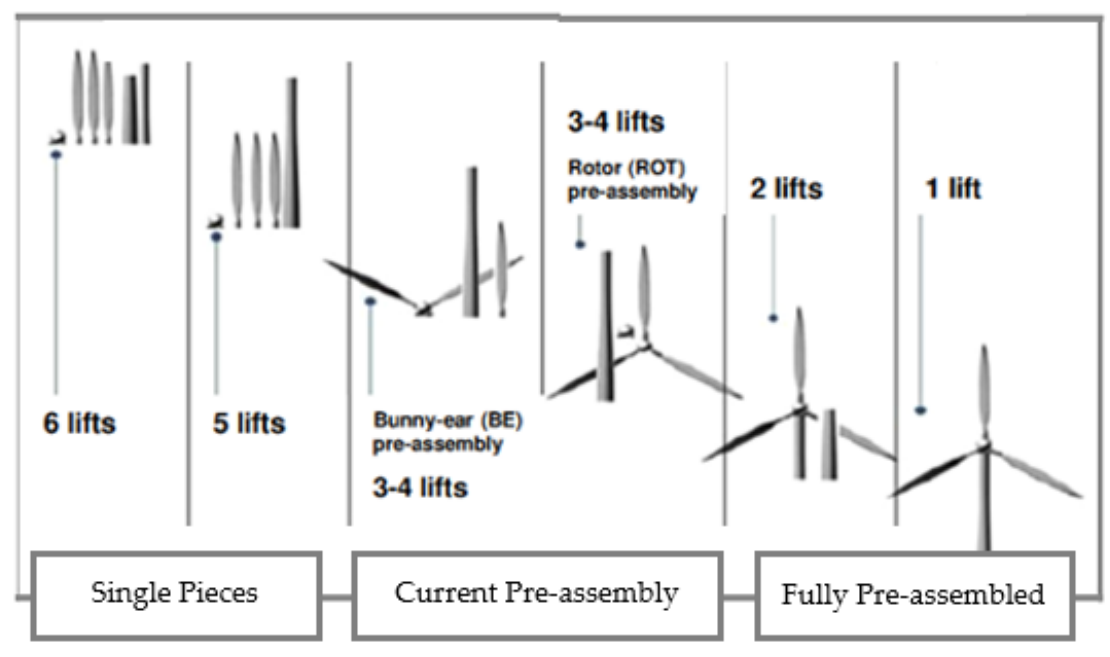

Figure 3. Offshore wind turbine current and proposed installation methods. Adapted from [20].

The turbine system can be transported offshore and installed in:

- Six lifting operations, transporting the turbine in single pieces (SP) [21], with the tower being split into two tower elements (2T), pre-assembling only the hub on the nacelle, and lifting each component separately. This solution can be employed where limitations in the design/operating capacity of equipment, or the stability of the installation unit (either vessel or barge) do not allow the entire tower (1T) to be lifted and transported.

- Five lifting operations, performed in the same way as the six-lifts method but without splitting the tower into two tower elements.

- From four to three lifting operations, such as for bunny-ear (BE) and rotor (ROT) pre-assembly methods.

- From two to a single lifting operation.

One thing is clear: the fewer lifts, the fewer human exposures to hazards. However, the installation of turbines must also remain cost-effective. Thus, possible use of alternative configurations for safety reasons must be balanced against the cost of installation. Therefore, different pre-assembly configurations and some self-erecting concepts are compared in the MCDA. However, safety of transporting single pieces can be improved: it has been found that when installing single blades, the critical motion radius can be reduced by up to $30 \%$ through the use of tuned mass dampers [22].

With regard to floating wind turbines, their placement on site differs in terms of their transportation, which is dependent on the specific concepts (semi-submersible, tension-leg platform (TLP) and spar substructures [23]). Vertical transportation of buoyancy- and mooring-stabilised 
platforms, such as 'WindFloat' [24] and that suggested in [25], have already been employed commercially for a demonstration project. On the other hand, ballast-stabilised designs can either be transported vertically (assembling the tower on the floater section in situ [26]) or horizontally, as proposed by the 'WindFlip' concept [27]. To elaborate on what is meant by the 'current pre-assembly' method, Table 2 shows examples of how many lifts have been performed per turbine for several North Sea wind farms.

Table 2. North Sea installation characteristics, adapted from [28-30].

\begin{tabular}{ccccccc}
\hline Project & MW Class & $\begin{array}{c}\text { No. Turbine } \\
\text { in the Farm }\end{array}$ & $\begin{array}{c}\text { No. Units to } \\
\text { Install }\end{array}$ & $\begin{array}{c}\text { Duration } \\
\text { (Days) }\end{array}$ & Method & $\begin{array}{c}\text { No. Lifts } \\
\text { per Turb. }\end{array}$ \\
\hline Horns Rev.1 & 2 & 80 & 2 & 110 & BE-1T & 3 \\
Prinses Amalia & 2 & 60 & 2 & $330 *$ & BE-1T & 3 \\
North Hoyle & 2 & 30 & 2 & 90 & BE-2T & 4 \\
Nysted & 2.3 & 72 & 1 & 78 & ROT-2T & 4 \\
Lillgrund & 2.3 & 48 & 1 & 73 & ROT-2T & 4 \\
OWEZ & 3 & 36 & 1 & 67 & BE-2T & 4 \\
Thanet & 3 & 100 & 1 & 197 & SP-1T & 5 \\
Greater Gabbard & 3.6 & 140 & 2 & $515 *$ & SP-2T & 6 \\
Lynn \& Inner Dowsing & 3.6 & 54 & 1 & 122 & SP-2T & 6 \\
Thornton Bank I & 5 & 6 & 2 & $70 *$ & ROT-2T ** & 6 \\
\hline
\end{tabular}

* Approximatively derived days from data available online [28]. The exact dates from the first to the last turbine erection involve also working breaks for foundation installation, weather window availability and unplanned issues.

** Tower(s) and nacelle components separately pre-installed with respect to the rotor pre-assembly.

\subsection{Concept Summary}

Table 3 summarises all concepts considered, ordered into their respective categories. For more detail on each item, a reference is given where possible next to their name in the table.

Table 3. List of options compared in initial stage MCDA.

\begin{tabular}{ccc}
\hline Guidance & Connections & Lifting Methods \\
\hline & Bolting robot arm [17,34,35] & Offshore Assembly, Single Pieces [30] \\
Remote Control [31,32] & Hydraulic Seafastening [36,37] & Current pre-assembly [30] \\
Tag lines/Tag line Winches [33] & Internal Jack Seafastening [38] & Bottom Fixed, Partially Self-Erecting Wind \\
High Wind-Boom Lock [13,33] & Friction Connection [16] & Turbines (WTs) [39,40] \\
Funnels/Cones [4] & External Climbing Bolt Robot & Bottom Fixed, Fully Self Erecting WTs \\
Multiple Cameras & ConXtech Connection [39] & Bottom Fixed, Fully pre-Assembled \\
Fish Eye lens & Bolt Conveyor & Transportation [41,42] \\
Lasers, Distance Measurement & Rotating Joint & Floating WTs, Vertical Transportation [24,25] \\
& Single, Large Thread & Floating WTs, Horizontal Transportation [43] \\
\hline
\end{tabular}

\section{Multi-Criteria Framework for Assessment of Human-Free Offshore Lifting Solutions}

\subsection{Introduction to $M C D A$}

Numerous ideas are presented in this work, all of which aim to reduce the exposure to risk for workers during operations. The selection of the optimum solution, however, cannot simply be based on intuition or a single criterion. A fully automated crane system, which can position blades into the hub without any human intervention, would eliminate the risk but it would also be costly to develop and has limited application in offshore conditions to date due to operational environment requirements. This constitutes a multi-dimensional problem lending itself to MCDA. MCDA divides a decision into smaller parts, analyzing each and then combining through a logical process to present an aggregated performance outcome.

MCDA methods can be applied to any decision with complexity and have been employed in the sustainable energy industry as a whole [44], and within the offshore wind sector [45]. 
In the state of the art regarding MCDA within the renewable energy industry, Kolios et al. [46] discussed using a stochastic input with a variety of methods including TOPSIS. MCDA is also widely applied in the renewable energy sector [45,47-50]. Authors outside of renewable energy have found stochastic MCDA useful, particularly when limited preference information is available [51,52]. Further research regarding the TOPSIS method is discussed in Section 3.3. The general process for an MCDA is shown in Figure 4.

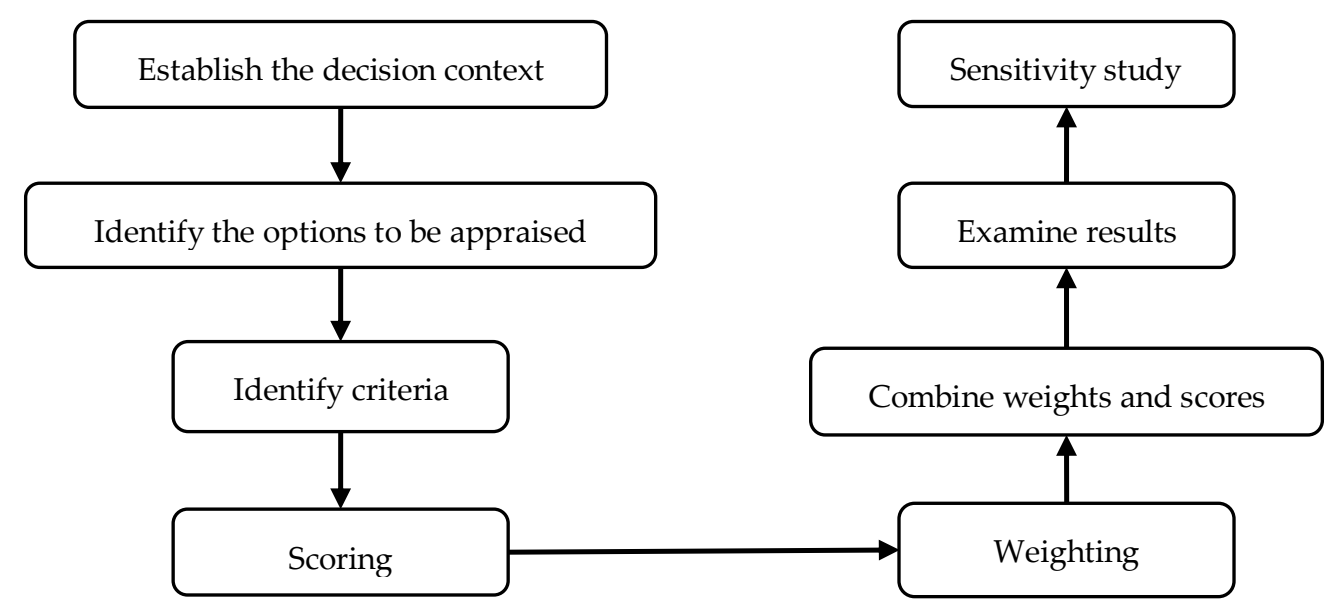

Figure 4. Process of an MCDA.

\subsection{Methodology}

The work involved a literature review and market search for existing technologies for reducing the human element in areas of high risk during lifting operations across industries. These included tools currently in use in industry, as well as new and conceptual designs proposed by the authors. Technologies were separated into three areas: guiding and control, connections, and assembly. Examples of these have been discussed in Section 2.

The methodology employed followed a structured path intended to make the best use of industry partners and maximise the effectiveness of the time and resources available and, finally, to produce a ranked list of options. The method is shown diagrammatically in Figure 5. The first step was to discuss the challenge with industry partners and assess incident data from offshore wind to determine what specific issues were faced and define the key areas of technology to be investigated. The next stage was to conduct a review of literature investigating potential technologies which either are designed for use in offshore wind or could potentially be applicable to offshore wind. At the same time, a survey was disseminated to those in the offshore wind industry through the industry partners with the aim of determining weights of the importance for a list of relevant criteria. The results from these last two steps were fed into the first stage of TOPSIS analysis as a method of filtering out 'bad' concepts and identifying promising concepts. After the first stage of TOPSIS, further study was conducted on the promising concepts, including an experiment testing guidance and control technologies. The purpose of this further research step was to obtain better data on the performance and applicability of the technologies for the intended purpose. This improved data was finally fed into a second stage TOPSIS analysis in order to produce a ranked list of the most promising technologies for those wishing to develop further and employ a human-free lifting solution for offshore wind. The important distinction of this method is that the literature review and the TOPSIS analysis (green and orange respectively in Figure 5) are performed twice. 


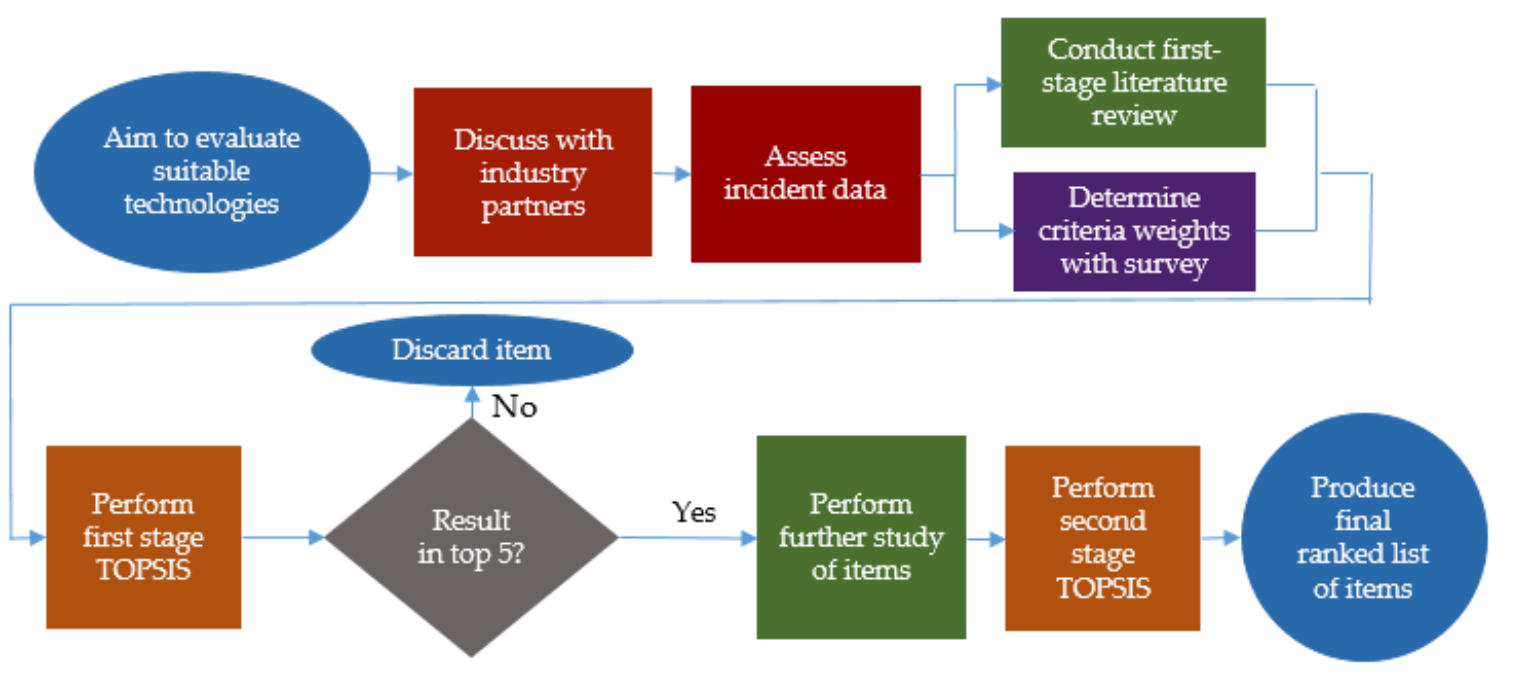

Figure 5. Flowchart outlining methodology employed in this work.

\subsection{TOPSIS}

There are numerous forms of MCDA; however, the 'TOPSIS' method was chosen to be used. The reason for this is that it is a straight-forward method that decouples the decision matrix from the weight vector and allows a combination of qualitative and quantitative criteria to be included in the analysis. It has also been utilised heavily for renewable energy problems, as summarised in [47].

The TOPSIS method was presented by Hwang and Yoon in 1981 [53]. TOPSIS is a simple method which utilises concepts of theoretical ideal positive and negative solutions and ranks alternatives by their Euclidian distance to these solutions [49].

The TOPSIS method is explained in references [47,54-56] but will also be presented here for reference with the following steps, which were applied using the criteria weighting and satisfaction values using a MATLAB (2015a, MathWorks, Natick, MA, USA) code:

1. A decision matrix is created holding the values for how well each alternative technology $m$ satisfies each criterion $n$.

2. The decision matrix is normalised by dividing each value by the square root of the sum of all values in the matrix squared, as shown in the following equation:

$$
r_{i j}=\frac{x_{i j}}{\sqrt{\sum x_{k j}^{2}}}
$$

where $r_{i j}$ is the weighted value in the decision matrix at point $(i, j)$ and $x_{k j}$ is the original value at that point.

3. The decision matrix is weighted by multiplying each value in the matrix by the criterion's corresponding weighting, as in the following equation:

$$
v_{i j}=w_{i} \times r_{i j}
$$

where $v_{i j}$ is the weighted, normalised value and $w_{i}$ is the weight value for that criterion.

4. A Positive Ideal Solution (PIS) and a Negative Ideal Solution (NIS) are created from the decision matrix. The PIS is the maximum of all of the 'good' criteria which the decision maker wants to maximise, and the minimum of all of the 'bad' criteria. The NIS is the converse of this. These solutions are purely theoretical and are used only for comparison. 
5. For each alternative, the geometric distance to the PIS and to the NIS, respectively, is determined. This is shown simply in the following equations:

$$
\begin{gathered}
D_{j}^{\mathrm{PIS}}=\sqrt{\sum_{i=1}^{n}\left(v_{i j}-v_{i j}{ }^{\mathrm{PIS}}\right)^{2}} \\
D_{j}^{\mathrm{NIS}}=\sqrt{\sum_{i=1}^{n}\left(v_{i j}-v_{i j} \mathrm{NIS}\right)^{2}}
\end{gathered}
$$

where $D_{j}{ }^{\mathrm{PIS}}$ is the distance of the $j^{\text {th }}$ alternative to the PIS, $D_{j}{ }^{\mathrm{NIS}}$ is the distance of the $j^{\text {th }}$ alternative to the NIS, and $v_{i j}{ }^{\text {PIS }}$ and $v_{i j}{ }^{\text {NIS }}$ are the weighted, normalised values of the $i j^{\text {th }}$ criterion for the PIS and NIS respectively.

6. How close each alternative is to the PIS relative to the NIS, is evaluated with the following equation:

$$
C_{j}=\frac{D_{j}^{\mathrm{NIS}}}{D_{j}^{\mathrm{PIS}}+D_{j}^{\mathrm{NIS}}}
$$

By using this closeness value $C_{j}$, which can have values in the range from 0 to 1 , the alternatives can finally be ranked. The closer the alternative is to 1 the better the alternative and the higher it is ranked.

\subsection{Stochastic Expansion of TOPSIS}

The TOPSIS method can be performed in a stochastic manner through the use of a Monte-Carlo method. In this way, weight values are randomly sampled from their respective fitted probability distribution. This process is repeated several times; in the case of this work, 100,000 iterations were performed. Through this repeated analysis the result is a range of values where the ranking can be different for each iteration. In this paper the mode rank is the primary value for comparison, but the mean $C$ value is also presented as a comparison to the deterministic $C$ value and deterministic ranking. The mode rank of an alternative is the rank which occurs most frequently in all of the iterations for that alternative.

\subsection{Industry Survey and Decision Matrix}

\subsubsection{Industry Survey}

A survey was sent out through $\mathrm{G}+$ and other company contacts via a link to an online survey and all information entered by respondents has been kept anonymous. A series of problem specific and contextual questions were included in order to capture the background of the respondent for future correlation to their responses. In total, there were 38 respondents from industry with an average of 10 years' relevant experience. In the survey the respondents were asked to provide their job title, years of experience, and their perceived level of expertise in the field; the target respondent would have any range of practical experience in offshore wind lifting operations. Ultimately, a bias towards (Health, Safety and Environment) HSE managers and managers in general was noticed; this is probably due to the network in which the link was shared, but which in general is more informed on the subject matter, hence adding value to the results. Both perceived experience and number of years have been used to weight the results, which is discussed further in Section 4.2.1. Next, the respondents were asked to weight each of the criteria discussed in Section 4.2 from 1-9 (1 being not important and 9 being extremely important). There was also an option to include any criterion that, in the respondent's opinion, was omitted from the survey and any general comments.

Firstly, there seemed to be an overriding theme that removing the human from beneath the load, rather than simply reducing occurrence, was important and that if the appropriate practice could be 
determined, cost would not be an issue, particularly as there is a legal requirement to do so 'when practicable'.

Secondly, this practice should be simple and reliable. There seemed to be some frustration with equipment complexity and that the complex equipment can be a burden to maintain. There was a desire for equipment which had a wider weather window and 'foolproof' use.

\subsubsection{Response Robustness}

Any analysis method is only going to be as good as its data input; therefore it is important to have confidence in the values obtained from the survey. A great deal of attention was paid to ensuring the quality of responses. The survey was only shared in specialist circles, a link was shared on LinkedIn by an industry contact in G+ and was also shared on the G+ website, and this made it unlikely that anyone not related to this field would see it.

Each response was checked individually to ensure no abnormalities, i.e., a repeated series of the same number or missing data. It should be noted that, for all 38 responses used, they had answered the survey fully. More than 38 responses were received, but some only answered the first half of the questions, so their responses were not included because it was felt that they were not fully committed to the survey. Two of the 38 respondents had less than 3 years of experience ( 0.33 and 2 years), but if their responses were removed it would had very little impact on the result; the average change in criterion weight was $0.83 \%$, and the highest change was only $2.66 \%$ for that particular criterion weight.

The average years of relevant offshore lifting experience for all of the 38 industry respondents was 9.9 years and had a maximum of 25 years. This indicates that the survey response is informed by a great deal of experience and that those who responded are representative of those within the industry who make the decisions. Anecdotally, the figures given by the respondent with the least experience did not differ significantly from the mean response; this indicates that using a minimum years' experience requirement would not necessarily have improved the result.

\section{Industry Survey and Application}

\subsection{Criteria Identification}

When considering implementing a new technology, the full timeline of developing and operating was reflected. Hence, the criteria were split into high-level groups of 'Research + Development', 'Operational', 'Manufacturing', and 'Other'. 'Research + Development' covers variables to implementation of the technology, 'Operational' defines important criteria during use, and 'Manufacturing' the attributes required to successfully produce the concept.

Each criterion can be seen in Figure 6 and is either positive or negative. For instance, when scoring an option on cost (negative variable) a lower value represents a more cost-effective option, i.e., cost of cameras 2, cost of self-erecting turbine 8 , showing that the cost of installing cameras is less and therefore more viable. The process for scoring these criteria, in terms of weight, and scoring the technologies in terms of 'Criteria Satisfaction' are discussed in Section 4.2. The criteria presented were subject to group discussions to investigate completeness, redundancy, and, importantly, mutual independence. Independent criteria are such that the score of one criterion does not affect another. At an extreme this poses the risk of 'double counting' which skews the decision matrix by adding weight to a property that has been split into categories that are intrinsically linked. The criteria chosen and their respective categories are shown in Figure 6. 


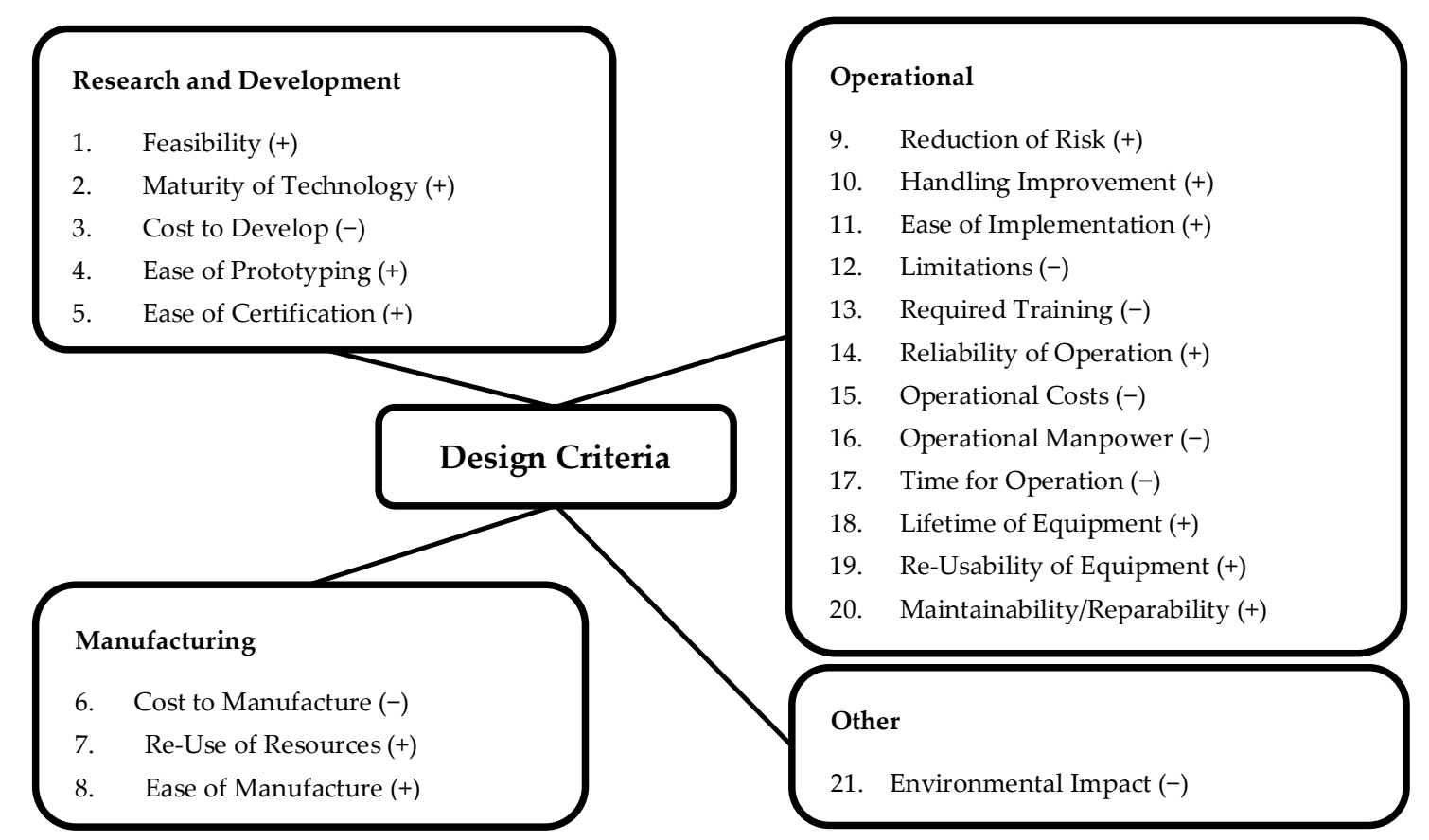

Figure 6. Criteria to be considered (+/ - indicate positive/negative variables).

\subsection{Scoring}

\subsubsection{Criteria Weights}

The weight values used for each criterion were the averages of the values given by respondents to the survey. As part of the survey, the number of years of relevant experience as well as the perceived level of expertise were requested and used to weight the value of the response. Figures 7 and 8 show the averaged responses from the survey which were used as weights for the deterministic MCDA. The blue bars are the averages of all of the responses while the orange and grey bars are weighted by perceived level of experience and by years of experience respectively. While these years' experience and perceived level of experience weights have some effect on the final values, it is minor. In this instance there is no significant correlation between experience by either measure and perceived level of importance of each criterion. It is important to note that in this case a linear weighting is applied, meaning that each response is multiplied by its experience value and the sum is divided by the sum of the experience values. A more noticeable difference may be seen if the shape function of weighting were to be changed, such as that in [55], in which a square weighting model produces larger factors between expertise ratings.

Table 4 shows what the coefficients such as $\mathrm{C} 1$ refer to for each distribution in Table 5 , which shows the distributions which best fit the response data. Distributions were fitted using Palisade @RISK and the distributions were chosen based on the Kolmogorov-Smirnov (K-S) goodness of fit index. Discrete distributions are presented, as the data set is discrete. However, in the stochastic analysis, which is described in Section 3.4., the continuous distributions were used as, in the TOPSIS analysis, there is no reason why the weight value must be an integer.

While items such as 'Reduction of Risk' had a very low standard deviation of 0.56 , indicating good agreement by all respondents, other items had a significantly larger standard deviation, for instance 'Environmental Impact', as it can be seen in Table 5. The mean value for all standard deviations was 1.70 . 
Table 4. Coefficients referred to for each distribution in Table 5.

\begin{tabular}{cccc}
\hline Distribution & 'C1' & 'C2' & 'C3' \\
\hline Binomial & Number of trials & Probability of success & - \\
Uniform & Minimum & Maximum & - \\
Poisson & Rate $\lambda$ & - & - \\
Extreme Value & a & b & - \\
Normal & Mean & Standard deviation & - \\
Triangular & Minimum & Most likely & Maximum \\
Logistic & Mean $\alpha$ & Scale $\beta$ & - \\
\hline
\end{tabular}

Table 5. Fitted distributions of weighting response data.

\begin{tabular}{|c|c|c|c|c|c|c|c|}
\hline Criteria & Discrete Dist. & $\mathrm{C} 1$ & $\mathrm{C} 2$ & Continuous Dist. & C1 & $\mathrm{C} 2$ & C3 \\
\hline Feasibility & Binomial & 10 & 0.78 & Extreme value & 8.47 & 0.98 & - \\
\hline Maturity of Tech & Binomial & 11 & 0.54 & Normal & 5.97 & 1.73 & - \\
\hline Cost to Develop & Binomial & 11 & 0.48 & Normal & 5.26 & 1.69 & - \\
\hline Ease of Prototyping & Uniform & 1 & 8 & Uniform & 0.81 & 8.19 & - \\
\hline Ease of Certification & Uniform & 2 & 9 & Uniform & 1.81 & 9.19 & - \\
\hline Handling Improvement & Binomial & 9 & 0.89 & Triangular & 4.66 & 9 & 9 \\
\hline Cost of Manufacture & Binomial & 12 & 0.47 & Logistic & 5.65 & 0.96 & - \\
\hline Ease of Manufacture & Binomial & 11 & 0.46 & Normal & 5.85 & 1.48 & - \\
\hline Reuse of Resources & Uniform & 2 & 8 & Uniform & 1.84 & 8.16 & - \\
\hline Environmental Impact & Uniform & 1 & 9 & Uniform & 0.78 & 9.22 & - \\
\hline Reduction of Risk & Binomial & 9 & 0.97 & Triangular & 6.87 & 9 & 9 \\
\hline Ease of Imp. and Op. & Binomial & 9 & 0.85 & Extreme Value & 8.23 & 0.94 & - \\
\hline Limitations & Binomial & 9 & 0.77 & Logistic & 7.06 & 0.81 & - \\
\hline Required Training & Poisson & 5.58 & - & Logistic & 5.72 & 1.14 & - \\
\hline Reliability of Operation & Binomial & 9 & 0.92 & Triangular & 4.86 & 9 & 9 \\
\hline Operational Costs & Binomial & 12 & 0.52 & Logistic & 6.30 & 1.02 & - \\
\hline Operational Manpower & Poisson & 5.58 & - & Extreme Value & 6.92 & 1.60 & - \\
\hline Time for Operation & Binomial & 10 & 0.72 & Extreme Value & 6.92 & 1.60 & - \\
\hline Lifetime of Equipment & Binomial & 11 & 0.54 & Extreme Value & 6.92 & 1.60 & - \\
\hline Reusability of Equipment & Binomial & 11 & 0.54 & Logistic & 6.20 & 1.09 & - \\
\hline Maintainability/Reparability & Binomial & 10 & 0.69 & Extreme Value & 6.92 & 1.60 & - \\
\hline
\end{tabular}

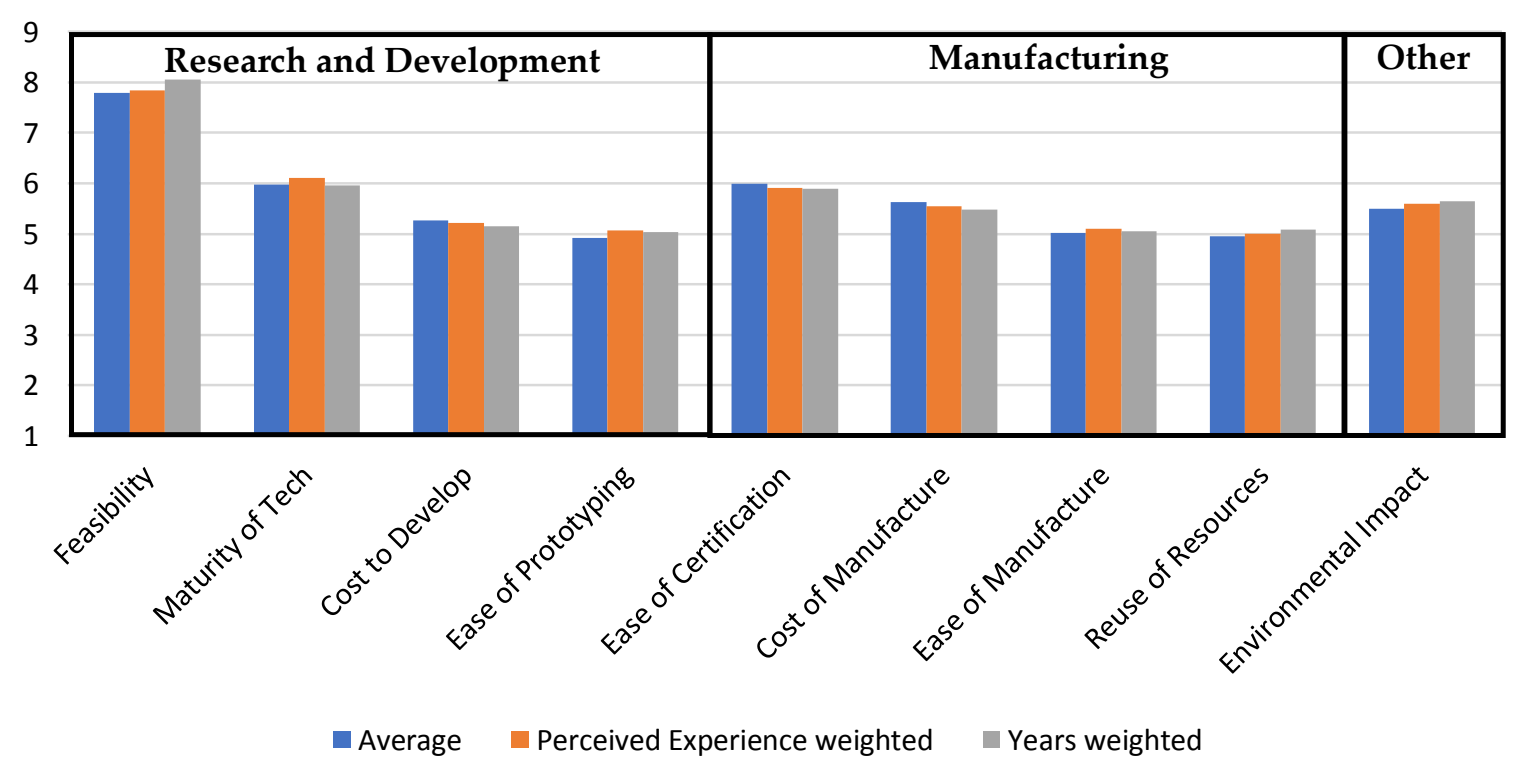

Figure 7. Averaged responses to the sections 'Research + Development', 'Manufacturing' and 'Other'. 


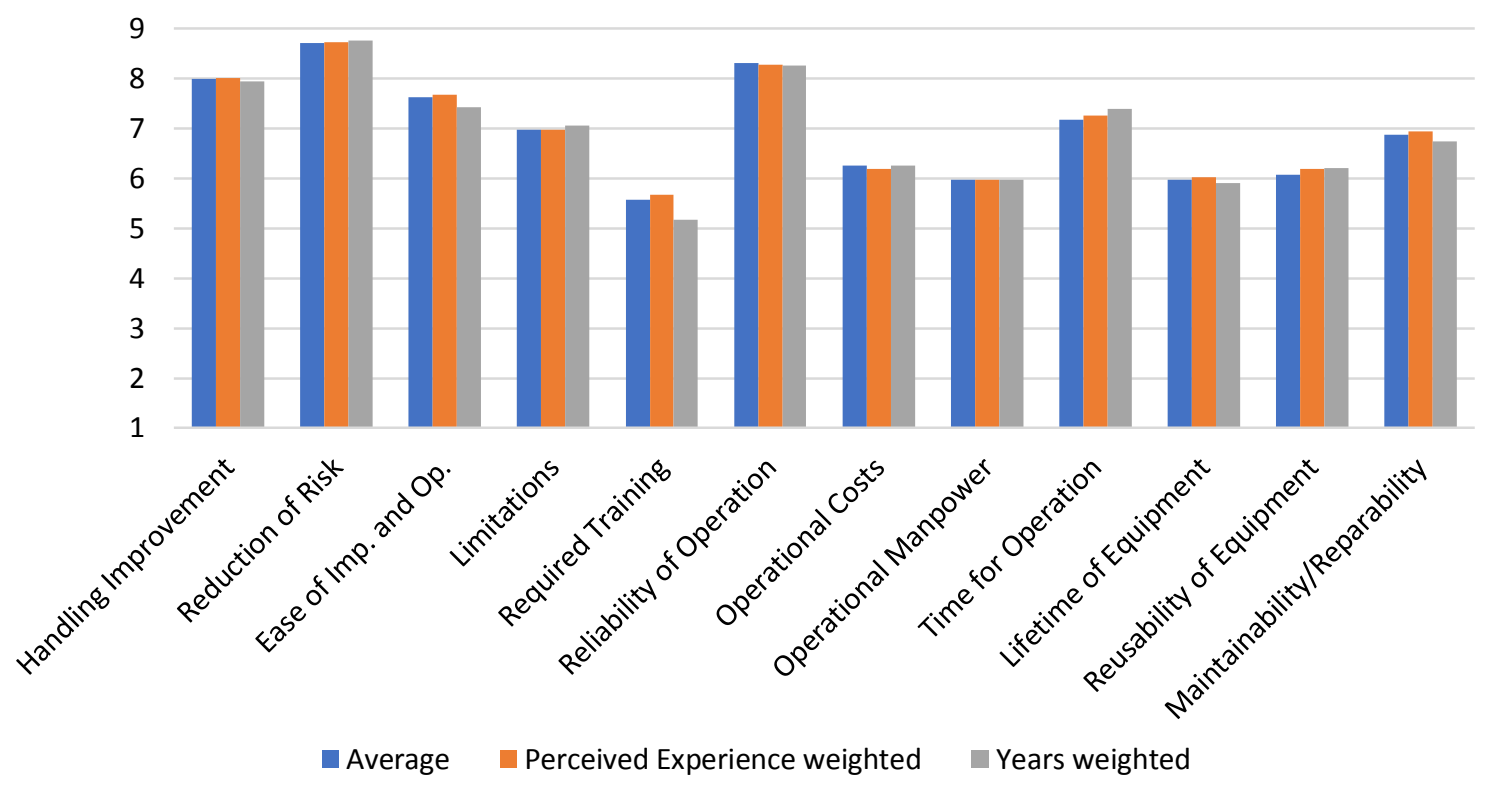

Figure 8. Averaged responses to the section 'Operational'.

\subsubsection{Decision Matrix}

One of the most challenging parts of this multi-criteria analysis is the determination of how well each alternative satisfies the criterion. If the technology is at a comparatively mature level of development, for example wind turbine support structures, then an empirical or quantitative method can be used to determine criteria satisfaction, as was the case in [46]. However, the technologies investigated in this study are not mature and, particularly in the initial stage of investigation, it may even be unclear what exactly the system or combination of systems consists of. Additionally, the technologies cover a broad range and are fundamentally very disparate. While an empirical method may be suitable to determine criteria satisfaction for one technology, the method may not be suitable for another and an alternative method may not be comparable. The actual numbers are not comparable if the technologies accomplish very different tasks; for example, one technology may cost significantly more than another but if it accomplishes a very different task it may be better value for what it does.

The criteria satisfaction was based on qualitative judgement as this is the only method that could be used for all categories. At the initial stage, the authors evaluated the technologies that they had respectively researched as they would be best placed to make that judgement. The Likert scale [56] was used, giving scores from 1 to 9 for each criterion to evaluate how well, or to what extent, that criterion was satisfied. The different sections were not compared to each other at this stage as the judgements of individuals are not comparable.

In the final stage, the authors scored all the technologies presented and these values were averaged. This was performed after a final presentation to ensure that everyone had an understanding of each other's sections. The average value was used to produce the final ranking; the decision matrix of this final stage can be seen in Table 6 . 
Table 6. Second stage Decision Matrix, averaged values. (Category numbers 1-21 as in Figure 6).

\begin{tabular}{|c|c|c|c|c|c|c|c|c|c|c|c|c|c|c|c|c|c|c|c|c|c|}
\hline \multirow{2}{*}{ Concepts } & \multicolumn{5}{|c|}{$R \& D$} & \multicolumn{3}{|c|}{ Man. } & \multicolumn{12}{|c|}{ Operational } & \multirow{2}{*}{$\begin{array}{c}\text { Oth. } \\
21\end{array}$} \\
\hline & 1 & 2 & 3 & 4 & 5 & 6 & 7 & 8 & 9 & 10 & 11 & 12 & 13 & 14 & 15 & 16 & 17 & 18 & 19 & 20 & \\
\hline $\begin{array}{l}\text { Boom Lock and } \\
\text { tag lines }\end{array}$ & 9 & 8 & 2 & 8 & 7 & 4 & 7 & 7 & 6 & 6 & 6 & 3 & 4 & 5 & 3 & 4 & 5 & 6 & 8 & 7 & 2 \\
\hline $\begin{array}{l}\text { Camera system + mech. } \\
\text { guidance }\end{array}$ & 7 & 5 & 5 & 7 & 6 & 5 & 6 & 6 & 8 & 7 & 8 & 5 & 5 & 7 & 4 & 4 & 3 & 4 & 7 & 6 & 3 \\
\hline $\begin{array}{l}\text { Robot arm for } \\
\text { seafastening }\end{array}$ & 8 & 7 & 6 & 5 & 6 & 6 & 5 & 7 & 7 & 8 & 7 & 4 & 5 & 6 & 5 & 3 & 4 & 7 & 8 & 8 & 3 \\
\hline $\begin{array}{l}\text { Boom Lock, tag lines, } \\
\text { cameras + mech. } \\
\text { guidance }\end{array}$ & 8 & 6 & 6 & 6 & 6 & 6 & 7 & 6 & 9 & 8 & 7 & 4 & 7 & 8 & 6 & 4 & 3 & 5 & 7 & 6 & 4 \\
\hline $\begin{array}{l}\text { Current pre-assembly } \\
\text { practice }\end{array}$ & 7 & 7 & 3 & 7 & 7 & 3 & 8 & 7 & 5 & 6 & 7 & 6 & 4 & 7 & 5 & 4 & 5 & 7 & 7 & 6 & 3 \\
\hline $\begin{array}{c}\text { Camera system }(3 \times \\
\text { fine tune, } 1 \times 360 \\
+ \text { redundancy })\end{array}$ & 7 & 7 & 4 & 7 & 6 & 2 & 7 & 7 & 6 & 6 & 5 & 4 & 6 & 5 & 2 & 4 & 6 & 5 & 7 & 6 & 2 \\
\hline $\begin{array}{l}\text { Robot arm for bolting } \\
\text { during construction }\end{array}$ & 7 & 6 & 7 & 5 & 6 & 6 & 5 & 6 & 7 & 7 & 6 & 5 & 4 & 7 & 5 & 3 & 4 & 7 & 8 & 8 & 3 \\
\hline $\begin{array}{c}\text { Completely hydraulic } \\
\text { seafastening }\end{array}$ & 7 & 6 & 5 & 5 & 6 & 6 & 4 & 6 & 7 & 7 & 6 & 5 & 4 & 6 & 4 & 3 & 4 & 6 & 7 & 6 & 4 \\
\hline $\begin{array}{l}\text { Offshore Assembly } \\
\text { (single pieces) } \\
\text { installation }\end{array}$ & 9 & 9 & 1 & 8 & 8 & 2 & 8 & 7 & 2 & 4 & 7 & 4 & 3 & 8 & 4 & 5 & 7 & 7 & 7 & 6 & 4 \\
\hline $\begin{array}{l}\text { Partially hydraulic } \\
\text { seafastening }\end{array}$ & 8 & 8 & 4 & 7 & 7 & 4 & 4 & 7 & 5 & 6 & 7 & 4 & 4 & 6 & 3 & 6 & 7 & 6 & 8 & 6 & 3 \\
\hline $\begin{array}{l}\text { Bottom fixed WTS } \\
\text { (Fully pre-assemb. } \\
\text { transportation) }\end{array}$ & 4 & 4 & 6 & 5 & 4 & 8 & 4 & 5 & 7 & 7 & 5 & 7 & 7 & 5 & 9 & 4 & 2 & 7 & 6 & 6 & 5 \\
\hline $\begin{array}{c}\text { Bottom fixed WTS } \\
\text { (Partially self-erecting) }\end{array}$ & 4 & 3 & 8 & 5 & 3 & 7 & 3 & 4 & 4 & 6 & 4 & 7 & 6 & 4 & 6 & 5 & 5 & 6 & 5 & 6 & 5 \\
\hline
\end{tabular}

This method of evaluation was deemed sufficient not only due to the inherent limitations but also in light of the objective of the MCDA. Initially, the MCDA was used to streamline options for further study; this was important so that the limited time available could be spent more efficiently and thoroughly, evaluating the ideas at this stage would be counter to that. The second stage was to provide a recommendation to industry for future development. The method used for the final stage was not entirely different from the method used to elicit criteria weightings-those knowledgeable on the subject were asked. For the early nature of this work, it was decided that this was sufficient to accomplish the intended aims.

\subsubsection{Stochastic MCDA}

The shape of distribution of the responses varied between the different criteria. Based on analysis of the response data using the @RISK extension of Excel from Palisade [57], the response distributions fit to five different probability distribution functions: Normal, Uniform, Triangular, Logistic, and Extreme Value; the distribution used for each criterion was chosen based on the goodness-of-fit parameters calculated by @RISK using the Kolmogorov-Smirnov index. This variation is demonstrated in the histograms shown in Figure $9 a-d$, their relative distribution is stated in the figure caption and the distributions of other criteria, including their coefficient values, are given in Table 5. This is supported by the approach used by Kolios et al. [47], where Monte Carlo (MC) simulation was used to perform the analysis and evaluate confidence in the output. An MC approach was also used in this study and will be compared with a deterministic approach to the same case. The stochastic expansion process is shown diagrammatically in Figure 10. 


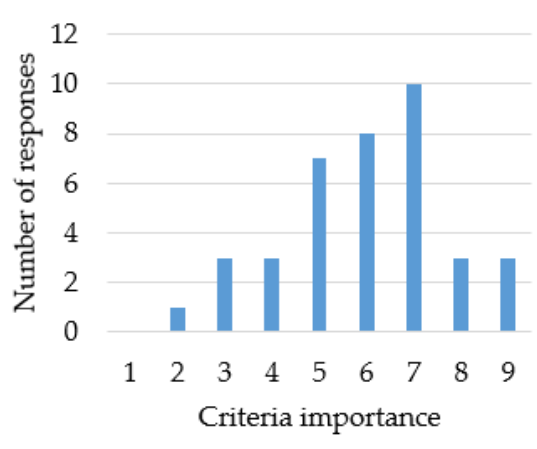

(a)

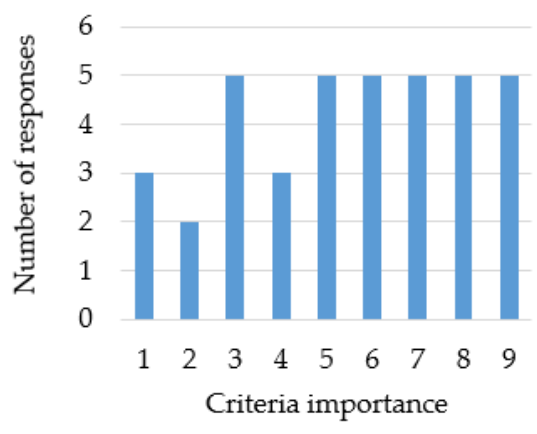

(c)

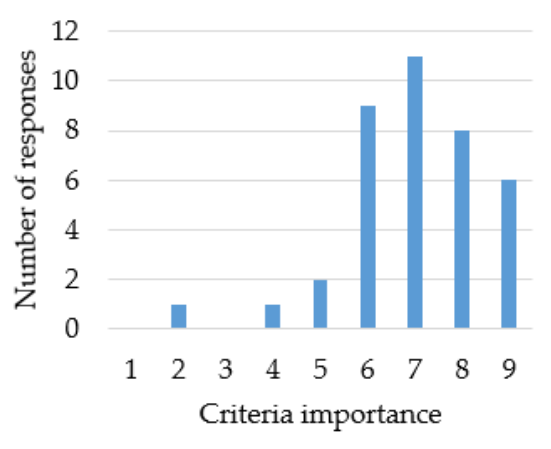

(b)

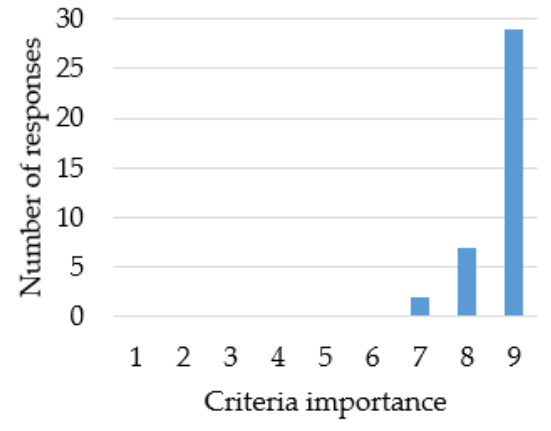

(d)

Figure 9. Probability distribution of responses for various criteria: (a) Maturity of technology, fit to a Normal distribution; (b) Limitations, fit to a Logistic distribution; (c) Environmental impact, fit to a Uniform distribution (d) Reduction of risk, fit to a Triangular distribution.

To perform the MC analysis in this study, 100,000 TOPSIS iterations were conducted, each time using weight values randomly generated from the alternative's respective continuous probability density function (PDF) shown in Table 5. A check was performed so that if the randomly generated value was either less than 1 or greater than 9, a new value would be generated for that iteration, ensuring that all weight values were within the defined limit. TOPSIS $C$ values and ranking of the alternatives are determined for each iteration. The mode rank for each alternative is then determined as well as for how many iterations the alternative rank is equal to its mode rank, as a percentage of the total number of iterations. The average $C$ value $\left(C_{\text {avg }}\right)$ and the standard deviation as a percentage of the alternative's $C_{a v g}$ are also presented. Finally, a deterministic TOPSIS is performed using mean response values for comparison, calculating TOPSIS $C$ values for each alternative and the alternative's rank.

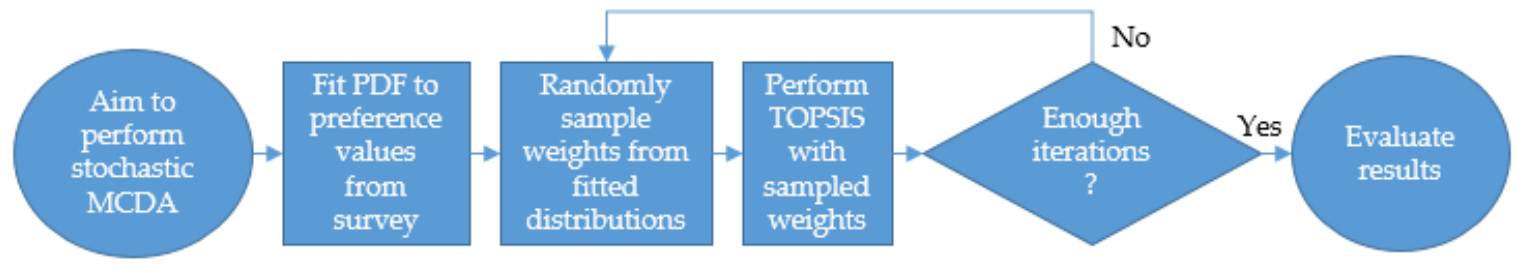

Figure 10. Process to stochastically expand MCDA. 


\section{Results and Discussion}

\subsection{Results}

\subsubsection{Stage 1 -Streamlining Within Categories}

Tables 7-9 show the top $50 \%$ of results from all of the ideas per category. These results can be compared within each table but cannot be compared between different tables due to the fact that the criteria satisfaction values were determined by different individuals and that they are separate TOPSIS analyses. Scaling of the values in each analysis on the normalisation stage is influenced by extreme values, so similar values between tables do not represent similar suitability.

Table 7 shows the results from the guidance and control section. Existing ideas such as guide pins and Boom Lock perform well due to the confidence in these comparatively simple ideas. Camera systems are at the bottom of these top ideas, possibly due to the uncertainty at this stage.

Table 8 shows the results from connections and seafastening. The top idea is automation of the bolting procedure followed by two novel seafastening methods and finally a new connection type.

Table 9 shows the initial results for the assembly section. Current pre-assembly methods, for example 'bunny ear' method, rank top followed by two full pre-assembly methods and finally the conventional method of constructing individual pieces at the site.

This initial analysis served as a guide to the research team rather than a fixed prescription, therefore the concepts chosen for each individual section may differ from those presented here.

Table 7. First stage TOPSIS results for 'Guidance and Control'.

\begin{tabular}{ccccc}
\hline $\mathbf{N}$ & Alternative & TOPSIS C & C, Experience Weighted & C, Year Weighted \\
\hline 1 & Guide Pins & 0.7124 & 0.7108 & 0.7126 \\
2 & Remote Control & 0.7099 & 0.7097 & 0.7077 \\
3 & Tag lines/Tag line winches & 0.6668 & 0.6681 & 0.6694 \\
4 & High Wind + Boom Lock & 0.6389 & 0.6409 & 0.64 \\
5 & Funnels/Cones & 0.6318 & 0.6307 & 0.6297 \\
6 & Multiple Cameras & 0.6268 & 0.6257 & 0.6299 \\
\hline
\end{tabular}

Table 8. First stage TOPSIS results for 'Connections and Seafastening'.

\begin{tabular}{ccccc}
\hline $\mathbf{N}$ & Alternative & TOPSIS C & C, Experience Weighted & C, Year Weighted \\
\hline 1 & Bolting robot arm & 0.6475 & 0.6495 & 0.6489 \\
2 & Hydraulic Seafastening & 0.6125 & 0.6127 & 0.614 \\
3 & Internal Jack Seafastening & 0.6125 & 0.6127 & 0.614 \\
4 & Friction connection & 0.5647 & 0.5645 & 0.5631 \\
\hline
\end{tabular}

Table 9. First stage TOPSIS results for 'Assembly Methods'.

\begin{tabular}{ccccc}
\hline $\mathbf{N}$ & Alternative & TOPSIS C & C, Experience Weighted & C, Year Weighted \\
\hline 1 & Current pre-assembly practice & 0.7187 & 0.7178 & 0.7203 \\
2 & Bottom fixed WTS (partially self-erecting WTs) & 0.5277 & 0.5293 & 0.5268 \\
3 & Bottom fixed WTS (fully pre assembled transportation) & 0.5078 & 0.5087 & 0.5076 \\
4 & Offshore assembly (single piece) installation & 0.5072 & 0.5069 & 0.5035 \\
\hline
\end{tabular}

\subsubsection{Stage 2-Global Ranking}

Further development of prospective technologies including experimental, design, and computational work was undertaken between stages 1 and 2. Final proposed ideas or suites of ideas developed in each section are compared directly to draw overall priorities and are presented in Table 10. The top five recommendations based on the final stage stochastic analysis are:

- Boom Lock and tag lines

- Automated bolt installation/fastening used for seafastening 
- Camera system with mechanical guidance

- Current pre-assembly practice of partially assembled components carried to the site for installation

- Boom Lock, tag lines, mechanical guidance and cameras

The results in Table 10 show that, by considering the analysis stochastically, the rank can change significantly for some of the alternatives. This suggests that, given a variety of distribution types, using the mean weight is not always appropriate. However, using the mean $C$ value to rank the alternatives, rather than the mode rank, the rank of alternatives would again change slightly. The mode rank is simply the rank which occurs most frequently for the alternative.

Table 10. Final ranking of all proposed ideas.

\begin{tabular}{|c|c|c|c|c|c|c|c|}
\hline \multirow{2}{*}{$\begin{array}{c}\text { Concept } \\
\text { Technology }\end{array}$} & \multicolumn{2}{|c|}{ Deterministic } & \multicolumn{5}{|c|}{ Stochastic } \\
\hline & Rank & $\mathrm{C}$ & Rank & $\begin{array}{l}\text { Mode } \\
\text { Rank }\end{array}$ & $\begin{array}{c}\% \text { Occ. of } \\
\text { Mode }\end{array}$ & Mean C & $\begin{array}{c}\text { Standard } \\
\text { Deviation of C }\end{array}$ \\
\hline Boom Lock and tag lines & 1 & 0.673 & 1 & 1 & 99 & 0.680 & 2.12 \\
\hline $\begin{array}{c}\text { Robot arm for } \\
\text { seafastening }\end{array}$ & 3 & 0.616 & 2 & 2 & 32.7 & 0.610 & 3.28 \\
\hline $\begin{array}{c}\text { Camera system }(3 \times \text { fine } \\
\text { tune, } 1 \times 360,+ \\
\text { redundancy })\end{array}$ & 6 & 0.589 & 3 & 2 & 24.4 & 0.600 & 3.98 \\
\hline $\begin{array}{c}\text { Camera system }+ \\
\text { mechanical guidance }\end{array}$ & 2 & 0.617 & 4 & 3 & 32.8 & 0.609 & 2.69 \\
\hline $\begin{array}{l}\text { Current pre-assembly } \\
\text { practice }\end{array}$ & 5 & 0.592 & 5 & 5 & 24.4 & 0.603 & 2.21 \\
\hline $\begin{array}{l}\text { Boom Lock, tag lines, } \\
\text { mechanical guidance and } \\
\text { cameras }\end{array}$ & 4 & 0.599 & 6 & 6 & 28.0 & 0.584 & 3.95 \\
\hline $\begin{array}{l}\text { Robot arm for bolting } \\
\text { during construction }\end{array}$ & 7 & 0.565 & 7 & 7 & 23.6 & 0.559 & 3.59 \\
\hline $\begin{array}{l}\text { Completely hydraulic } \\
\text { seafastening }\end{array}$ & 8 & 0.556 & 8 & 8 & 30.2 & 0.553 & 2.87 \\
\hline $\begin{array}{c}\text { Offshore Assembly } \\
\text { (single pieces) installation }\end{array}$ & 9 & 0.546 & 9 & 9 & 21.4 & 0.561 & 4.26 \\
\hline $\begin{array}{l}\text { Partially hydraulic } \\
\text { seafastening }\end{array}$ & 10 & 0.545 & 10 & 10 & 34.6 & 0.550 & 3.98 \\
\hline $\begin{array}{l}\text { Bottom fixed WTS (fully } \\
\text { pre-assembled } \\
\text { transportation) }\end{array}$ & 11 & 0.390 & 11 & 11 & 100.0 & 0.371 & 7.21 \\
\hline $\begin{array}{c}\text { Bottom fixed WTs } \\
\text { (partially self-erecting) }\end{array}$ & 12 & 0.236 & 12 & 12 & 100.0 & 0.229 & 6.46 \\
\hline
\end{tabular}

\subsection{Discussion}

There are three main areas where this work is useful and provides insights: the collation of useful technologies, survey results from industry, and the stochastic MCDA process.

The concepts discovered in the process are important for the industry. Some of these concepts, such as the robotic arm for seafastening, are currently a long way from being implemented, but others, such as the use of cameras and physical guidance, could be implemented potentially in the near future. The end output from this method is both a broad review of technologies with an in-depth review of highly ranked technologies. The authors hope that this work can help lead to a reduction in significant offshore wind heavy lifting incidents.

The results from the industry survey are both useful for this work, but also potentially useful for other work in the future. The survey results show that there is little disagreement that reduction of risk is extremely important but it also shows that it is not the only important value. The next three highest criteria were 'reliability of operation', 'handling improvement' and 'feasibility'. The cost to develop the technology and how easy it is to manufacture seemed relatively unimportant, but 
not negligible. This shows a strong desire in offshore wind to improve the safety of offshore lifting operations. One should bear in mind, however, that this survey was conducted specifically in the context of technologies intended to improve the health and safety in offshore wind heavy lifting operations and that applying the findings outside of this context may not be valid.

Typically, MCDA analyses are applied in a single stage; however, in this work the TOPSIS method was applied in two stages. This method allowed for a more efficient use of resources when conducting the work and potentially resulted in producing a more useful list of technologies. There were some challenges in applying this approach. One challenge was that some technologies only had a limited amount of information available for them and if most of the sources were discovered in the first stage then there is little new information on them in the second stage. Conversely, if significant new information is discovered on a technology in the second stage, making it more or less favourable, then the question has to be asked if the first stage was really accurate and should it have been repeated. While both concerns are valid, in the first case the implications are not significant and in the second they can be dealt with. Overall the method of applying an MCDA in two stages appears to work well for this kind of work where the first stage is used to guide the application of resources as more information is gathered.

The outcome of the second stage MCDA illustrates that Boom Lock and tag lines are the most promising concepts to be taken forward. This seems reasonable as both aspects are fully developed products such that their technology readiness level is high, and when combined they provide a less risky and cost-effective solution to the problem. It should be noted that there are some limitations to these results, most notably subjective and qualitative scoring of the concepts within each category.

\section{Conclusions}

This paper presents a framework for deciding upon the most suitable solution to health and safety problems and has described a selection of concepts for human-free offshore lifting operations when installing wind farms. Concepts have been explored with a view to reducing the need for people to be beneath suspended loads and thus improve the safety of the operations. Safety, though, is not the only criterion to consider when introducing new technologies to an industry. For this reason, a multi-criteria decision analysis method was used to evaluate concepts aiming to better inform future decisions but also to give a final recommendation for further development. A survey was distributed to industry personnel contacts with relevant experience and was used to elicit weighting values for use in the MCDA. The results of the survey showed not only which criteria were most important but also how opinion varied across the industry on some criteria as there was not always general agreement among respondents. Technologies were evaluated qualitatively in two stages for criteria satisfaction values. A summary of the ideas most worth developing has been presented. Based on the survey, criteria such as 'reduction of risk', 'handling improvement', and 'reliability of operation' were most important while 'ease of manufacture', 'required training', and 'reuse of resources' were less important. The most highly recommended concepts are:

1. Boom Lock and tag lines-These are control elements which improve handling and reduce risk by providing more contact with the load at key points.

2. Camera system and mechanical guidance-These give guidance as well as a level of fine control without which it would have required operators to be physically present.

3. Robot arm for seafastening-This concept was proposed by the authors and consists of a robot bolting system, a concept used in shop floor construction, for completing the seafastening operation.

4. Boom Lock, tag lines, mechanical guidance, and cameras-This is a combination of the first two recommendations. It is lower than both recommendations because using both increases complexity and difficulty in implementation, as well as cost. 
5. Current pre-assembly practice-This is as opposed to either the 'single pieces' or 'fully pre-assembled' methods discussed in Section 2.3. However, it has to be kept in mind that other pre-assembly methods can have advantages in the right circumstances.

While some of the recommended concepts still need to be developed further, the realisation of other concepts, such as the use of cameras and physical guidance, is expected to be feasible already quite soon. Thus, this work should contribute to making lifting operations in the offshore wind industry safer. Besides the focus on health and safety, the conducted survey in this work also showed that reliability, ease of handling, and feasibility of new technologies are of high relevance for the offshore wind energy industry.

The decision analysis framework developed can be applied in similar future problems, and be further expanded in a more detailed analysis, by having a quantitative scoring scheme for the scoring of different decision alternatives against each of the selected criteria. Furthermore, the applied approach of a two stage TOPSIS analysis presented a new method-as a potential alternative to the typical single stage MCDA - with which resources can be used more efficiently and very valuable results can be obtained in the second stage due to the focused approach.

Author Contributions: M.R., T.B., P.C., D.C. and M.L. conceived the work and undertook literature reviews, experimental work and wrote various sections of this paper. T.B. set-up and sent out the survey and collated the paper. M.R. analyzed the data using the MCDA framework. A.K. and F.B. steered the work and gave invaluable advice.

Acknowledgments: This work was supported by grant EP/L016303/1 for Cranfield University, Centre for Doctoral Training in Renewable Energy Marine Structures (REMS) (http:/ / www.rems-cdt.ac.uk/) from the UK Engineering and Physical Sciences Research Council (EPSRC) and the G+ consortium.

Conflicts of Interest: The authors declare no conflict of interest.

\section{References}

1. Szulecki, K.; Fischer, S.; Gullberg, A.T.; Sartor, O. Shaping the 'Energy Union': Between national positions and governance innovation in EU energy and climate policy. Clim. Policy 2016, 16, 548-567. [CrossRef]

2. Voormolen, J.A.; Junginger, H.M.; van Sark, W.G.J.H.M. Unravelling historical cost developments of offshore wind energy in Europe. Energy Policy 2016, 88, 435-444. [CrossRef]

3. Wind Europe. The European Offshore Wind Industry—Key Trends and Statistics 2016; Wind Europe: Brussels, Belgium, 2017.

4. Forewind. HSE Case Study 2: The 'Human Free' Met Mast Installation; Forewind: London, UK, 2013.

5. G+. Global Offshore Wind Health and Safety Organisation. 2017. Available online: https://www. gplusoffshorewind.com/ (accessed on 21 August 2017).

6. G9 Offshore Wind Health \& Safety Association. 2014 Incident Data Report; G9 Offshore Wind Health \& Safety Association: London, UK, 2014.

7. G+ Offshore Wind Health \& Safety Association. 2016 Incident Data Report; G+ Offshore Wind Health \& Safety Association: London, UK, 2016.

8. G9 Offshore Wind Health \& Safety Association. 2015 Incident Data Report; G9 Offshore Wind Health \& Safety Association: London, UK, 2015.

9. Maes, K.; Roeck, G.D.; Lombaert, G. Motion tracking of a wind turbine blade during lifting using RTK-GPS/INS. Eng. Struct.. in press.

10. Kaur, A.; Watkins, S.E.; Moss, R.H.; Luechtefeld, R.A. Vehicle Positioning Using Image Processing. In Proceedings of the SPIE The International Society for Optical Engineering, San Diego, CA, USA, 3-4 August 2009.

11. Rahman, M.S. Machine Vision Techniques for Crane Workshop Mapping; University of Louisiana: Lafayette, LA, USA, 2015.

12. Rinner, B.; Guggi, H. Distributed Smart Cameras for Hard Real-Time Control. In Proceedings of the 2011 Fifth ACM/IEEE International Conference on Distributed Smart Cameras, Ghent, Belgium, 22-25 August 2010; pp. 234-237. 
13. High Wind. The Boom Lock. 2014. Available online: http://www.high-wind.eu/boomlock/ (accessed on 25 January 2017).

14. Krabbendam, R. Tag Line Winches-The Capstan Winch and Tag Line Masterwinch. Heavy Lift Nezws. 2015. Available online: http: / www.heavyliftnews.com/news/tag-line-winches---the-capstan-winch-and-tagline-masterwinch (accessed on 28 April 2018).

15. Ku, N.; Roh, M., II. Dynamic Response Simulation of an Offshore Wind Turbine Suspended by a Floating Crane; Taylor \& Francis: Abingdon, UK, 2015.

16. Heistermann, C.; Husson, W.; Veljkovic, M. Flange connection vs. friction connection in towers for wind turbines. In Nordic Steel and Construction Conference; Stålbyggnadsinstitutet: Stockholm, Sweden, 2009; pp. 296-303.

17. Sydenham, M.W.; Brown, T. Robotic Installation of OSI-Bolts; SAE International: Warrendale, PA, USA, 2015.

18. Video: Fistuca BLUE Wedge Connection. Available online: https://www.youtube.com/watch?v= asDQzEuaCdc (accessed on 5 May 2018).

19. Wang, W.; Bai, Y. Investigation on installation of offshore wind turbines. J. Mar. Sci. Appl. 2010, 9, $175-180$. [CrossRef]

20. Kuijken, L. Single Blade Installation for Large Wind Turbines in Extreme Wind Conditions; Technical University of Denmark: Kongens Lyngby, Denmark; TU Delft: Delft, The Netherlands, 2015.

21. Jiang, Z. The impact of a passive tuned mass damper on offshore single-blade installation. J. Wind Eng. Ind. Aerodyn. 2018, 176, 65-77. [CrossRef]

22. Ahn, D.; Shin, S.; Kim, S.; Kharoufi, H.; Kim, H. Comparative evaluation of different offshore wind turbine installation vessels for Korean west-south wind farm. Int. J. Nav. Archit. Ocean Eng. 2016, 9, 45-54. [CrossRef]

23. European Wind Energy Association. Deep Water; European Wind Energy Association: Brussels, Belgium, 2013.

24. Principle Power. Principle Power's WindFloat Concept Animation; Principle Power: Emeryville, CA, USA, 2011.

25. Amate, J.; Sánchez, G.D.; González, G. Development of a Semi-submersible Barge for the installation of a TLP floating substructure. TLPWIND ${ }^{\circledR}$ case study. J. Phys. Conf. Ser. 2016, 749, 12016. [CrossRef]

26. Video: offshoreWIND.biz. Mating of Hywind Scotland Floating Turbines. Available online: https:// www.offshorewind.biz/2017/06/26/mating-of-hywind-scotland-floating-turbines-video/ (accessed on 5 May 2018).

27. Soe-Jensen, A. Method for Establishing a Wind Turbine on a Site, Transport of a Wind Turbine Tower, Wind Turbine Tower and Vessel Suitable for Transporting a Wind Turbine Tower. U.S. Patent 2010/0281820 A1, 9 December 2010.

28. 4C Offshore. Wind Farm Installation Specification. 2017. Available online: http://www.4coffshore.com/ windfarms (accessed on 4 April 2017).

29. C-power. Thornton Bank Wind Farm Specification. 2017. Available online: http://www.c-power.be/index. php/project-phase-1/effective-works (accessed on 4 April 2017).

30. Uraz, E. Offshore Wind Turbine Transportation \& Installation Analyses: Planning Optimal Marine Operations for Offshore wind Turbines. Master's Thesis, Gotland University, Visby, Sweden, 2011.

31. RCT. Remote Control Technologies (RCT) GuidanceSystem Testing-Dorothy Drives. 2012. Available online: https:/ / www.youtube.com/watch?v=DDhxZ35ndg0 (accessed on 23 January 2017).

32. Ruff, T.M. Development and Testing of a Computer-Assisted Remote-Control System for the Compact Loader-Trammer; United States Department of the Interior: Washington, DC, USA, 1992.

33. De Maesschalck, K. Crane Rails: Why They Improve Offshore Lifting Capabilities. The High Wind Challenge. 2016. Available online: https:/ /highwind.editionmanager.com/2016/12/02/crane-rails-why-they-improveoffshore-lifting-capabilities / (accessed on 7 May 2018).

34. Hörauf, L.; Müller, R.; Bauer, J.; Holger, N.; Vette, M. Development of an Intelligent Bolt Tensioning System and Adaptive Process for the Automated Pitch Bearing Assembly of Wind Turbines. In Advances in Sustainable and Competitive Manufacturing Systems; Springer: Berlin, Germany, 2013; pp. 661-663.

35. Müller, R.; Hörauf, L.; Vette, M.; Martin, J.L.S.; Alzaga, A.; Hohmann, J.; Althoefer, K.; Würdemann, H. Robot guided bolt tensioning tool with adaptive process control for the automated assembly of wind turbine rotor blade bearings. Prod. Eng. 2014, 8, 755-764. [CrossRef] 
36. Møller, J. Siemens: Optimized Concepts for Loading \& Installing Offshore wind Turbines. Available online: https: / www.slideshare.net/IQPCGermany/siemens-optimized-concepts-for-loading-installingoffshore-wind-turbines (accessed on 5 May 2018).

37. Hoeksema, W. Innovative Solution for Seafastening Offshore Wind Turbine Transition Pieces during Transport Innovative Solution for Seafastening Offshore Wind Turbine Transition Pieces during Transport No. February; TuDelft: Delft, Netherlands, 2014.

38. Bijlaard, F.S.K.; Coelho, A.M.G.; Magalhães, V.J.D.A. Innovative joints in steel construction. Steel Constr. 2009, 2, 243-247. [CrossRef]

39. Dehlsen, J.G.P.; Mikhail, A.S. Self-Erecting Tower and Method for Raising the Tower. U.S. Patent 6,955,025 B2, 18 October 2005.

40. Hau, E. Wind Turbines; Springer: Berlin, Germany, 2008.

41. Theconstructionindex. Blyth Debut for BAM Gravity Base Foundations. Available online: https:// www.theconstructionindex.co.uk/news/view/blyth-debut-for-bam-gravity-base-foundations (accessed on 6 April 2017).

42. Zhang, P.; Han, Y.; Ding, H.; Zhang, S. Field experiments on wet tows of an integrated transportation and installation vessel with two bucket foundations for offshore wind turbines. Ocean Eng. 2015, 108, 769-777. [CrossRef]

43. Barker, P. A Flipping Good Idea for Floating Turbines. Available online: http:/ /www.maritimejournal.com/ news101/marine-renewable-energy/a-flipping-good-idea-for-floating-turbines (accessed on 5 May 2017).

44. Wang, J.J.; Jing, Y.Y.; Zhang, C.F.; Zhao, J.H. Review on multi-criteria decision analysis aid in sustainable energy decision-making. Renew. Sustain. Energy Rev. 2009, 13, 2263-2278. [CrossRef]

45. Lozano-Minguez, E.; Kolios, A.J.; Brennan, F.P. Multi-criteria assessment of offshore wind turbine support structures. Renew. Energy 2011, 36, 2831-2837. [CrossRef]

46. Kolios, A.; Mytilinou, V.; Lozano-Minguez, E.; Salonitis, K. A comparative study of multiple-criteria decision-making methods under stochastic inputs. Energies 2016, 9, 566. [CrossRef]

47. Macharis, C.; Ampe, J. The use of multi-criteria decision analysis (MCDA) for the evaluation of transport projects: A review. In Proceedings of the EURO 2007 Conference, Prague, Czech Republic, 4 September 2007; pp. 1-12.

48. Vagiona, D.G.; Karanikolas, N.M. A multicriteria approach to evaluate offshore wind farms siting in Greece. Glob. Nest J. 2012, 14, 235-243.

49. Mateo, J. Multi-Criteria Analysis in the Renewable Energy Industry; Springer: New York, NY, USA, 2012.

50. Papavasiliou, A.; Oren, S.S. Stochastic Modeling of Multi-Area Wind Power Production. In Proceedings of the 2015 48th Hawaii International Conference on System Sciences, Kauai, HI, USA, 5-8 January 2012.

51. Wang, Y.; Mai, Y.; He, W. A Quantitative Approach for Benefit-Risk Assessment Using Stochastic Multi-Criteria Discriminatory Method. Stat. Biopharm. Res. 2016, 8, 373-378. [CrossRef]

52. Saint-Hilary, G.; Cadour, S.; Robert, V.; Gasparini, M. A simple way to unify multicriteria decision analysis (MCDA) and stochastic multicriteria acceptability analysis (SMAA) using a Dirichlet distribution in benefit-risk assessment. Biometr. J. 2017, 59, 567-578. [CrossRef] [PubMed]

53. Hwang, C.-L.; Yoon, K. Multiple Attribute Decision Making: Methods and Applications; Springer: Berlin/Heidelberg, Germany, 1981.

54. Kolios, A.J.; Rodriguez-Tsouroukdissian, A.; Salonitis, K. Multi-criteria decision analysis of offshore wind turbines support structures under stochastic inputs. Ships Offsh. Struct. 2016, 11, 38-49.

55. Kolios, A.; Read, G.; Ioannou, A. Application of multi-criteria decision-making to risk prioritisation in tidal energy developments. Int. J. Sustain. Energy 2016, 35, 59-74. [CrossRef]

56. Likert, R. A technique for the measurement of attitudes. Arch. Psychol. 1932, 22, 55.

57. Palisade @risk, software. Available online: https://www.palisade.com/risk/ (accessed on 5 May 2018).

(C) 2018 by the authors. Licensee MDPI, Basel, Switzerland. This article is an open access article distributed under the terms and conditions of the Creative Commons Attribution (CC BY) license (http:/ / creativecommons.org/licenses/by/4.0/). 